\title{
As Origens Ambivalentes do Conservadorismo. O lugar de Edmund Burke na História do Pensamento Político
}

\author{
Paulo Henrique Paschoeto Cassimiro*
}

\section{Resumo}

O presente artigo visa discutir alguns pontos do debate sobre as interpretações da obra de Edmund Burke, tendo em vista três perspectivas gerais. As interpretações que buscam em sua obra os fundamentos da tradição do pensamento conservador e que encontram em Nisbet e Russell Kirk alguns de seus principais intérpretes. A tradição da história das ideias e seu mais importante representante, Isaiah Berlin, que inclui Burke na categoria dos pensadores chamados contra-iluministas. E, por fim, a interpretação de J. G. A. Pocock que procura contextualizar autores como Gibbon, Hume, Adam Smith e Burke dentro da perspectiva de um iluminismo diverso daquele caracterizado hegemonicamente pelo movimento das ideias na França do século XVIII.

Palavras-chave: Conservadorismo; Revolução; lluminismo; Contralluminismo.

\section{Abstract}

The Ambivalent Origins of Conservatism. Edmund Burke's Place in the History of Political Thinking.

This article aims to discuss some points of the debate about Edmund Burke's work interpretations, in view of three general perspectives. The interpretations that seek in his work the foundations of the conservative thought tradition and that find in Nisbet and Russell Kirk some of its main interpreters; the tradition of the history of ideas and its most important representative, Isaiah Berlin, which includes Burke in the category of thinkers called counter-enlightenment; and finally the interpretation of J. G. A. Pocock and Gertrude Himelfarb that seeks to contextualize authors such as Gibbon, Hume, Smith and Burke within the perspective of an enlightenment different from that hegemonically characterized by the movement of ideas in eighteenth-century France.

Keywords: Conservatism - Revolution - Enlightenment - CounterEnlightenment

\footnotetext{
* Doutor e mestre em ciência política pelo IESP-UERJ, é graduado em ciências sociais pela Universidade Federal Fluminense. Email: phpcassimiro@gmail.com.
} 


\section{Introdução}

Temos observado nos últimos anos um reflorescimento do interesse tanto acadêmico quanto do público em geral pelo tema do pensamento conservador. Um grande número de obras têm sido publicadas recentemente nos Estados Unidos ${ }^{1}$ voltadas à discussão da tradição do pensamento conservador. Mesmo no Brasil, a publicação recente das obras de Russel Kirk, um dos principais ideólogos de tradição conservadora americana, além de algumas obras de divulgação de cunho geral², mostram que o interesse do público pelo tema vem se expandindo.

Em quase todos estes trabalhos encontramos em comum o nome de Edmund Burke emergindo como o primeiro elo, o autor fundamental da cadeia de pensadores que formam aquilo que poderia se chamar de uma tradição do pensamento conservador, calcada numa concepção de sociedade orgânica, baseada em valores tradicionais e numa hierarquia que emerge da natural desigualdade das relações sociais, um tipo de conservadorismo que continua uma certa tradição romântica ${ }^{3}$, reação à paulatina diferenciação social introduzida com o avanço do capitalismo na Europa dos séculos XVIII e XIX. Porém, o exato lugar da obra de Burke ainda é objeto de disputas nos debates de história do pensamento político. Apesar da inegável importância que sua obra legou ao pensamento contrarrevolucionário, Burke era um whig, partidário dos

\footnotetext{
1 Para alguns exemplos mais recentes, ver: Brown, Frederick. 2014. The Embrace of Unreason. France 1914-1940. New York: Knopf. Lefer, David. 2013. The Founding Conservatives. How a Group os Unsung Heores Saved the American Revolution. New York: Penguin Books. Levin, Yuval. 2013. The Great Debat: Edmund Burke, Thomas Paine and the birth of Right and Left. New York: Basic Books. Lilla, Mark. 2008. The Stillborn God: Religion, Politics and the Modern West. New York: Vintage Books. Scruton, Roger. 2007. A Political Philosophy: Arguments for Conservative. London: Bloomsbury Academic.

${ }^{2}$ Coutinho, João Pereira. 2014. As Idéias Conservadoras Explicadas a Revolucionários e Reacionários. São Paulo: Três Estrelas, 2014. Kirk, Russell. 2012. A Era de T. S. Eliot: A imaginação Moral do Século XX. São Paulo: É Realizações; 2013. A Política da Prudência. São Paulo: É Realizações.

${ }^{3}$ Devido às limitações do presente trabalho, não nos aprofundaremos na discussão da relação entre a obra de Burke e as diversas vertentes do romantismo. Caracterizado de forma mais geral como uma reação ao lluminismo, o romantismo, contudo, não se limita à expressões da crítica à modernidade filosófica e social. O Romantismo pode mesmo se expressar como otimismo com relação ao universalismo revolucionário. Na Inglaterra, a obra de autores como o poeta William Wordsworth ou a filósofa e ensaísta Mary Wollstonecraft revelam várias afinidades entre romantismo e revolução. Para uma distinção mais acurada das diversas correntes do romantismo, ver: Löwy, Michel; Sayre, Robert (1993). Romantismo e Política. Rio de Janeiro, Paz e Terra.
} 
que combatiam com afinco a concentração do poder nas mãos do Rei e dos que defendiam o papel da Common Law como fator civilizatório das colônias. No presente artigo procuraremos avaliar algumas das contribuições mais importantes para esclarecer e mapear o complexo debate sobre a obra de Sir Edmund Burke.

\section{Burke e a História das Ideias Conservadoras}

A literatura sobre Burke, especialmente aquela de língua inglesa, está dividida tendo em vista dois interesses distintos em sua obra. Por um lado, há uma vasta bibliografia que desenvolve-se a partir dos estudos sobre literatura e retórica, procurando entender a relação de Burke com a vida literária e cultural de seu tempo e a relação entre a retórica e as ideias políticas. O exemplo mais interessante dos estudos literários sobre Burke é o artigo de Franz de Bruyn, The Literary Genres of Edmund Burke: The Political Uses of Literary Form (1996), um estudo sobre os usos da linguagem e dos gêneros literários nos escritos de Burke. Quanto à bibliografia propriamente voltada à teoria política de Burke, podemos encontrar duas tendências distintas. A primeira compreende Burke como um autor fundamentalmente voltado para temas de política prática e imediata, que nega as formulações teóricas do iluminismo por seu caráter abstrato e afirma em contraposição uma leitura utilitarista e pragmática da política. Segundo Peter J. Stanlis (1996), Sir Leslie Stephen, em seu trabalho The History of English Thought in the Eighteenth Century (1881), é o principal defensor, ainda no século XIX, da leitura de Burke como um político utilitarista. Harold Laski em sua obra Political Thought in England (1920) apresenta uma leitura semelhante, que enxerga Burke como um político liberal reagindo aos abusos violentos perpetrados pela Revolução Francesa. Mais próximo de nosso tempo, The Useful Cobbler: Edmund Burke and the Politics of Progress (1994) apresenta uma visão mais próxima daquelas leituras pragmáticas de Burke. Para seu autor, James Conniff, Burke reconhece na filosofia de seu tempo a ausência de um padrão comum de julgamento do intelecto, voltando-se para a história na busca de fundamentos seguros para a política.

Em 1929, Alfred Cobban, um importante historiador inglês, publicaria Edmund 
Burke and the Revolt Against Eigtheenth Century: A Study of the Social and Political Thinking of Edmund Burke. Cobban produziria o primeiro estudo mais complexo do ponto de vista da história das ideias sobre a relação da obra de Burke com os diversos movimentos de crítica ao iluminismo e com as bases do romantismo no século seguinte.

No pós-guerra, a leitura e a produção acadêmica sobre Burke iriam sofrer uma mudança acentuada com relação à geração anterior. Em 1952 apareceria pela primeira vez reunidos em um volume os diversos artigos que Leo Strauss havia começado a publicar dois anos antes, a partir de uma conferência proferida em 1949 na Universidade de Chicago, sob o título Natural Right and History (1952). A obra apresenta a leitura de Strauss sobre a mudança do conceito de direito natural desde os antigos gregos até o século XVIII. Em seu estudo, Strauss apresenta uma pequena reflexão sobre Burke, na qual o autor inglês aparece como um defensor da antiga ideia de lei natural baseada nos antigos, especialmente em Cícero, contra o conceito de direito natural moderno. Para Strauss, apesar de Burke buscar uma reconciliação com a fundamentação da ordem dos antigos, o problema da história como fundamento da ordem política exerce um papel central em sua reflexão política, marcando uma conciliação ao fim impossível com a ideia antiga de lei natural. Na esteira de Strauss, Peter J. Stanlis publica em 1955 uma obra fundamental para a bibliografia burkeana, Edmund Burke and the Natural Law. A partir da distinção entre lei natural (natural law) e direito natural (natural right), Stanlis persegue a hipótese de que o conceito de lei natural, na tradição de Cícero e dos católicos medievais, fundamenta a concepção de ordem de Burke. O trabalho de Stanlis apresenta análises importantes sobre a crítica ao conceito revolucionário de direitos naturais e sobre a concepção burkeana de natureza humana. Um ano depois, Charles Parkin publicaria The Moral Basis of Burke's Political Thought (1956), um sucinto, porém fértil, trabalho sobre os problemas do estado de natureza, dos direitos naturais e da concepção de ordem moral na obra de Burke.

No mesmo período, Russell Kirk, um dos principais ideólogos do conservadorismo de corte anglo-saxão, publicaria The Conservative Mind: From Burke to Santayana (1953), obra que mais tarde ainda seria revisada e acrescida de novos 
autores. Kirk tenta estabelecer a linhagem conservadora através das ideias de um conjunto de autores que, segundo ele, moldaram a forma da mentalidade conservadora. Kirk atribui à obra de Burke o início do que seria definido por ele como a tradição conservadora, caracterizada justamente pela crítica aos princípios racionalistas e materialistas que definem a filosofia moderna, cujo auge havia sido alcançado com o movimento do iluminismo francês no século XVIII. Anos mais tarde, Kirk ainda publicaria Edmund Burke: A genius Reconsidered (1967), mais uma obra dedicada à defesa de Burke como o pai da reação conservadora à modernidade. Nos anos 50 ainda seria publicado o ensaio "The Counter-enlightenment" de Isaiah Berlin, mais tarde reunido no volume Against the Current. Essays in The History of Ideas (1978), onde o influente autor britânico desenvolveria pela primeira vez sua hipótese sobre a existência de uma tradição contra-iluminista da qual Burke faria parte. Segundo Berlin, o contrailuminismo e seus principais autores, como Vico, Herder e Burke, forneceriam as bases teóricas do romantismo, definido como um movimento em oposição ao iluminismo, caracterizado pelo irracionalismo e pela defesa das tradições históricas contra a abstração da razão especulativa.

As obras de Berlin e Kirk são o centro de uma interpretação que retoma a tentativa de distinguir uma tradição conservadora dentro do debate da história das ideias, identificando lugares comuns e afinidades teóricas entre diversos autores, sem um esforço mais acentuado de contextualização histórica. Em termos históricos, a relação de Burke com o partido Tory, que em 1830 assumiria o nome de "Conservative Party", sempre fo ambígua. Burke foi durante toda a vida um Whig identificado não só com os ideais, mas também com os estratos sociais dos quais provinham os quadros do partido - eminentemente pequenos e médios proprietários cujas terras haviam sido adquirias após os cercamentos e profissionais liberais de origem urbana. Mesmo durante a Revolução Francesa o partido Whig abrigava tanto entusiastas quanto críticos do movimento. A defesa de Bruke dos interesses americanos, a simpatia explicita aos católicos irlandeses e, principalmente, a polêmica em torno do caso Hastings - liderada por Burke e apoiada pro seus companheiros Whigs - colocaram-no em diversos momentos em oposição radical aos Tories e à Coroa. James Sack (in Crowe, 1997:76) mostra como, da morte de Burke em 1797 até a formação do Partido Conservador, seu 
nomeraramente aparecia nos debates públicos na Inglaterra ligado ao partido Tory. Ele registra ainda que nenhuma honra pública foi prestada ao ex-parlamentar quando de sua morte. Não surpreende o fato de que Burke permanecesse um autor de certa forma relegado ao esquecimento pelos Tories quando sabemos que, quando da primeira publicação de sua correspondência em 1844, causou grande repercussão as diversas demonstrações de simpatia de Burke pelo catolicismo, além de críticas ao potencial divisionista do protestantismo na Inglaterra.

Sack registra ainda que, em meio à diversidade de escritos surgidos em jornais e revistas durante a reforma do partido conservador nos anos 30 do século XIX, os nomes que apareciam como os "pais" ideológicos do novo partido eram, principalmente, os de Bolingbroke - a quem Burke satirizou em seu escrito Vindication on Natural Society - e do Dr. Samuel Johnson. Sack cita uma passagem do Quarterly Review de 1881 que atribui a Bolingbroke a responsabilidade pela "grande revolução que transformou o torismo de Filmer e Rochester no torismo de Johnson e Pitt" (Idem, 1997:78-79). Ele lembra ainda que, na primeira grande obra sobre o movimento Tory, History of Toryism, publicada em 1886, o autor, T. E. Kebbel, cita como heróis tories políticos como Pitt, Canning, Wellington, Peel e Disraeli, fazendo apenas uma referência modesta a Burke no capítulo sobre a Revolução Francesa. Até mesmo Benjamin Disraeli, que na sua imaginação de romancista crítico do mundo moderno possui muitos pontos em comum com Burke, critica suas posições whigs. Disraeli, profundamente influenciado pela ideia romântica de que a industrialização havia dissolvido os laços que mantinham em pé a estrutura hierárquica da sociedade inglesa, com os nobres no topo - mesmo sendo ele um judeu de origem burguesa - não poderia fazer concessões a muitas das posições liberais do whig Edmund Burke. Porém, como Burke pode ter sido transformado pelos ideólogos conservadores e estudiosos da história das ideias em um dos mais importantes - ou mesmo o mais importante - pensador conservador?

Mannheim procurará estabelecer os pressupostos sociológicos da ideia conservadora. Segundo ele, as ideias não podem ser compreendidas se não estiverem situadas em seu contexto social. As ideais que constituem o que ele chama de 
"mentalidades utópicas" são respostas a determinadas circunstâncias sociais. Mannheim começa por afirmar que o caráter conservador é eminentemente antiteórico. Ao contrário das utopias progressistas, que estabelecem um objetivo futuro no processo histórico, a matéria de pensamento dos conservadores é o próprio presente, assimilando a ele a sobrevivência de ideais que são transmitidos por meio da tradição. Enquanto o tradicionalismo caracteriza-se pela preservação de formas de vida e de ordem social estabelecidas a longo prazo e sedimentadas sob o solo da religião, da hierarquia social e da cultura entendida como um corpo orgânico, o conservadorismo se torna a expressão de um pensamento que - partindo de princípios tradicionalistas "torna-se um movimento relativamente autônomo no processo social" (Mannheim, 1986:156). A própria consciência conservadora só será despertada quando colocada diante das ideias de seus oponentes, que representam o risco do rompimento da estabilidade da ordem do mundo.

\footnotetext{
Somente o contra-ataque de classes oponentes e a sua tendência a romper com os limites da ordem existente irá motivar a mentalidade conservadora para questionar as bases de seu domínio, ocasionando necessariamente, entre os conservadores, as reflexões histórico-filosóficas concernentes a eles mesmos. Surge, dessa forma, uma contra-utopia que serve como um meio de autoorientação e de defesa (Mannheim, 1968:253).
}

Para Mannheim, o desenvolvimento da mentalidade conservadora se dará no sentido da crítica à ausência de concretude da especulação metafísica do pensamento liberal e socialista, contrapondo-Ihes a experiência histórica dos povos. Contra a norma formal e especulativa das mentalidades progressistas, os conservadores afirmarão as conquistas da cultura, das leis e da arte. Daí deriva a afirmação do tradicionalismo, que caracteriza precisamente o pensamento conservador. Mannheim estabelece assim, com precisão, a forma sociológica das circunstâncias em que o conservadorismo surgiu como mentalidade consciente. Porém, como essa mentalidade permanece? Como ela se reproduz a ponto de formar uma tradição expressiva na história das ideias?

Nisbet interpreta o conservadorismo como uma ideologia política; uma das três ideologias mais influentes dos últimos dois séculos. Apesar daqueles que afirmam que o conservadorismo não poderia ser definido como uma ideologia, por não possuir ideais e princípios bem definidos, Nisbet insiste em defini-lo dessa forma. Para ele, "ideologia é qualquer conjunto de ideias morais, econômicas, sociais e culturais razoavelmente 
coerentes, possuindo uma relação sólida e óbvia com a política e o poder político; mais especificamente, é uma base de poder para possibilitar o triunfo de um conjunto de ideias" (Nisbet, 1987:9). Nisbet faz uma advertência importante, ao afirmar que as ideologias tem expressão tanto na formulação das idéias políticas quanto na execução dos movimentos e partidos políticos, sem significar, contudo, que haja entre eles uma correspondência rígida. A prática política, que lida com as circunstâncias do momento histórico, nem sempre corresponde exatamente às ideias que as motivam. Assim, ele irá procurar na tradição conservadora as características fundamentais que definem a feição do conservadorismo enquanto ideologia política. Nisbet lembra que o primeiro partido nomeadamente conservador, o "conservative party" só nasceria na Inglaterra em 1830. Porém, as bases teóricas do partido conservador inglês, haviam surgido quarenta anos antes, com a publicação das Reflections on the Revolution in France. Nisbet afirma que grande parte das características, argumentos e ideias principais que compuseram as ideias conservadoras encontram sua origem na obra de Edmund Burke, torando-o o gerador de toda a tradição conservadora.

Russell Kirk, por outro lado, não concorda com Nisbet quanto ao caráter ideológico do pensamento conservador. Para Kirk,

\begin{abstract}
Talvez seja mais correto, na maior parte do tempo, usar a palavra "conservador" essencialmente como um adjetivo. Não existiria, assim, um modelo conservador, e o conservadorismo é uma negação da ideologia: ele é um estado da mente, um tipo de personalidade, uma forma de olhar para a ordem social. A atitude que chamamos conservadorismo é sustentada por um corpo de sentimentos, e não por um sistema de dogmas ideológicos. Podemos quase dizer que um conservador pode ser definido como uma pessoa que se compreende como tal. O movimento conservador ou o corpo de opiniões conservadoras podem acomodar uma diversidade considerável de visões e de temas; não existe um teste ou um conjunto de artigos que estabeleça o credo conservador $^{4}$ (Kirk, 1993:28).
\end{abstract}

A caracterização de Kirk contrasta com a tentativa sociológica de Nisbet de definir a categoria de ideologia para encaixar qualquer tipo de movimento político moderno. Se a ideologia, segundo Nisbet, caracteriza-se por um certo "apelo público" à

\footnotetext{
${ }^{4}$ Todas as citações de obras em inglês ou francês foram traduzidas pelo autor do artigo, mantendo a referência bibliográfica da edição no idioma original.
} 
ação-e, nesse sentido, conservadorismo, liberalismo ou socialismo podem ser incluídos nesta categoria - Kirk busca uma caracterização "psicológica" do conservadorismo que, ao mesmo tempo, é contrastada com o conceito de ideologia entendido como "dogmática política". Porém, Kirk ainda assim insiste em afirmar a paternidade de Burke. Para ele, o pensamento conservador se revela através de alguns princípios - como a crença numa ordem moral, o reconhecimento dos costumes e das tradições e a suspeição com relação à mudança - que podem ser deduzidos da tradição formada por determinados pensadores que têm características em comum e que deitam raízes no pensamento de Edmund Burke. Sua obra The Conservative Mind estabeleceu o cânone da tradição conservadora anglo-saxã. Longe de significar um esforço histórico para investigar a raiz e os desdobramentos de algo que poderia ser chamado uma tradição conservadora, Kirk esforça-se por construir uma relação de afinidade entre as ideias de diversos autores que, para ele, tiveram papel fundamental na construção de uma "mentalidade conservadora". O argumento, como já nos referimos, parte de um princípio de identificação "psicológica" e que, portanto, só pode ser identificado $a$ posteriori. A compreensão da forma mentis conservadora, de acordo com Kirk, é um exercício da crítica cultural, e não de historiografia ou de análise sociológica. Kirk afirma que a tradição burkeana - sem nunca perder a dimensão da crítica à modernidade permaneceu, desenvolveu-se e ocupou um importante espaço entre as correntes políticas dos séculos XIX e XX. John Adams, Samuel Coleridge, Benjamin Disraeli, John Newman, Irving Babbitt, Georges Santayana e T. S. Eliot são alguns dos nomes que Kirk aponta como os mais importantes da tradição conservadora que começa com Edmund Burke.

Poderíamos dizer que, a despeito de sua negação da identificação entre conservadorismo e ideologia, a reflexão de Kirk tem, por si mesma, um caráter ideológico, no sentido apontado por Nisbet. Ela se insere no contexto do reflorescimento da crítica cultural conservadora nos Estados Unidos do pós-guerra. A tentativa de fomentar uma "opinião pública conservadora", formada por um instrumental intelectual que escapasse do status quo acadêmico, levou a formulação de uma série de trabalhos que buscavam relacionar a importância de valores tradicionais e o fortalecimento do sentido de comunidade no seio de uma sociedade assolada pelo 
risco do radicalismo de esquerda e da expansão das funções sociais do Estado ${ }^{5}$. 0 esforço de Nisbet, por outro lado, é orientado por uma tendência consideravelmente distinta. Ele procura, através de um exercício de história das ideias no estilo de Arthur Lovejoy, estabelecer relação entre as ideias de diversos autores e encontrar as afinidades que produzam um sentido comum de pertencimento de suas obras a uma determinada tradição. Existiria, portanto, uma lógica intrínseca às ideias e obras de tais autores que, através do esforço comparativo do estudioso, nos mostraria uma certa tradição, possível de ser apresentada de forma coerente e conectada. Contudo, como já apontou a crítica do historiador Quentin Skinner ${ }^{6}$ à história das ideias tradicional, tal gênero de reflexão carece de uma substancial contextualização histórica. Para afirmarmos a existência de uma tradição, seria preciso demonstrar uma série de condições - a possibilidade real da recepção de uma obra em um determinado autor e a sua permanência como fonte fundamental dessa mesma tradição por um determinado período de tempo, por exemplo - que a história das ideias instituída por Lovejoy, especialmente em torno da célebre revista Journal of the History of Ideas, toma como pressupostas. Deixemos, contudo, a crítica contextualista em suspenso por um momento, e nos dediquemos à reflexão do mais influente intérprete da história das ideias no século XX, o filósofo russo radicado na Grã-Bretanha, Isaiah Berlin.

\section{Burke e o Contra-Iluminismo}

Uma das interpretações mais influentes sobre o pensamento de Burke e de outros autores conservadores é a obra de Isaiah Berlin, que evoca a categoria de contrailuminismo (counter-enlightenment) para designar uma série de pensadores que

\footnotetext{
${ }^{5}$ Não podemos aqui adentrar à complexa e diversificada variedade do movimento conservador norteamericano, no qual a obra de Russel Kirk representa apenas uma das interpretações e tendências possíveis. Para mais informações sobre o tema, ver: NASH, George. The Conservative Movement in America since 1945. Delaware: ISI Books, 2014; Gottfried, P. E. Conservatism in America. Nova York: Palgrave Macmilian, 2009.

${ }^{6}$ Para mais, ver especialmente o texto "Meaning and Understanding in the History of Ideas". History and Theory. Vol. 8, n¹ (1969), pp. 3-53.
} 
representariam uma outra face da modernidade relegada a segundo plano por se opor ao movimento do iluminismo reinante a partir de fins do século XVII. A importância e influência de Berlin nos leva a uma reflexão mais detida sobre seu argumento. Os fundamentos do que mais tarde seria caracterizado como o pensamento lluminista que afloraria durante o século XVIII encontram-se no século anterior. Aquilo que Paul Hazard caracterizou como "les grandes changements psychologiques" em sua obra clássica La Crise de la conscience européene. 1680-1715 prepararam o espírito europeu para as grandes mudanças culturais, filosóficas e políticas que surgiriam no século XVIII. Hazard nos revela como os pressupostos filosóficos da modernidade finalmente ganham nesse período a hegemonia no pensamento europeu. A vitória do "espírito geométrico" é o primeiro passo rumo à nova forma do espírito europeu. Tanto Hazard quanto o historiador israelita Zeev Sternhell ressaltam a célebre "querelle" entre os Antigos e os Modernos como um momento importante na vida cultural européia para a preparação do espírito dos homens para a grade mudança. A famosa "querelle" produziu uma ruptura sem precedentes na história cultural do ocidente. Se, por um lado, a grande mudança nas letras ocidentais provocada pelo fim da antiguidade Romana e o surgimento do cristianismo como centro do espírito ocidental procurou adaptar o conteúdo que a nova religião demandava às formas artísticas tradicionais clássicas, a "querelle" representou antes a transformação das formas e dos temas clássicos em favor de um tratamento novo, que ressaltasse a superioridade dos eventos e dos homens modernos. Assim, Charles Perrault discursa sobre a superioridade de Luís XIV sobre os grandes Imperadores romanos e Fenélon escreve sobre a superioridade da virtude dos santos cristãos sobre os heróis gregos e romanos. (Hazard, 2009:273). presente é visto então como superior ao passado e não deve à grandeza da Antiguidade mais do que a admiração e o respeito adequados. Assim, pela primeira vez aparece de maneira clara na história cultural européia o indício de uma visão de mundo que percebe a modernidade como um passo além, como o progresso do espírito humano com relação à antiguidade.

Nesse contexto intelectual, o conceito de crítica surge como o elemento principal na formação das filosofias modernas. A crítica da ordem política reinante, da história, do direito e da religião em nome da razão é o que permite, acima de tudo, abarcarmos 
uma série de autores tão díspares em torno de um mesmo nome e de uma mesma tradição a que chamamos de lluminismo. O conceito de crítica apresenta-se como o principal elemento de produção da ruptura radical com o passado e com seus elementos normativos. A ruptura produz, em consequência, a convicção moderna de que os homens podem, munidos do uso da razão, avaliar, questionar e até mesmo abdicar dos pressupostos tradicionais e construir por si mesmos os princípios que organizam e orientam a vida humana. Berlin aponta que essa crença moderna na capacidade humana de criar através da razão uma ideia que oriente a ordem da vida em sociedade é o ponto central das filosofias políticas modernas e, por conseguinte, o elemento contra o qual os pensadores críticos da modernidade se voltaram com maior fúria. A razão da modernidade libertaria os homens para a descoberta não só do universo físico, mas da história, da antropologia e de estruturas sociais e políticas novas.

\footnotetext{
Rousseau e Kant mostram, assim, que o homem é perfectível e que esta perfectibilidade é a negação continua da natureza, afirmando a construção do homem por ele mesmo e, em consequência, a historicidade inerente à experiência humana. Esta historicidade é um deslanchar-se contínuo das determinações naturais (...). O homem é guiado por certas faculdades comuns a todos os homens em todos os tempos e em todo lugar. Essas faculdades, ainda que pouco desenvolvidas, portam em germe o signo de uma liberdade infinita cujo desenvolvimento é concebido como um processo de destacamento da natureza e de Deus. (Sternhell, 2006:54)
}

De acordo com essa interpretação, o iluminismo alçaria a faculdade crítica da razão em instrumento de aperfeiçoamento da condição humana, o instrumento para o progresso e a felicidade. À razão caberia, portanto, revelar o erro e a verdade e, sendo idêntica em todos os homens, torna-se o único instrumento do espírito humano capaz de encontrar aquilo que de universal existe. Assim, o preconceito é o primeiro elemento a ser superado para que a razão possa dar aos homens seu entendimento próprio e lhes permita alcançar as leis naturais e morais através do uso correto da filosofia crítica. Segundo Sternhell, "a lei é oposta ao arbitrário, pois ela é universal e permite resolver o problema que Rousseau anunciou: é preciso encontrar uma forma de laço social no qual sejamos livres mesmo sendo constrangidos a obedecer" (/dem, 2006:63). A lei em Kant encontra-se no polo oposto da lei nas concepções de Herder e Burke, por exemplo. Se a 
lei, para Kant, é o fruto da razão após a superação dos preconceitos e superstições, para os contra-iluministas a lei é justamente a sedimentação que tais preconceitos e superstições depositam na história dos povos e dos homens.

A autonomia da razão, a rejeição racional à autoridade tradicional, a afirmação de conceitos como aperfeiçoamento, crítica e esclarecimento caracterizam em linhas gerais o movimento Iluminista. Isaiah Berlin define o movimento intelectual do lluminismo francês da seguinte forma:

\begin{abstract}
As doutrinas centrais dos pensadores franceses progressistas, a despeito dos desacordos internos entre eles, se sustentam na crença, enraizada na antiga doutrina da lei natural, de que a natureza humana foi sempre a mesma em todos os tempos e lugares; assim, as variações locais e históricas não têm importância comparadas com o centro constante daquilo que pode definir o homem como uma espécie distinta dos animais, dos minerais e das plantas (Berlin, 2001:1).
\end{abstract}

Berlin apresenta uma visão do iluminismo e de sua reação, que ele nomeia de contra-iluminismo, a partir do argumento sobre o universalismo da razão contra o particularismo da história. Se o mundo é governado por princípios universais e inalteráveis que regem não só a natureza como os eventos da vida humana, e a descoberta desses princípios pode garantir a compreensão dos fins de épocas e civilizações, o ataque à crença na capacidade humana de descobrir esses princípios constitui a mais fértil e intelectualmente influente reação à modernidade.

Berlin elege como autor paradigmático do contra-iluminismo o filósofo napolitano Giambattista Vico. Para Vico, o racionalismo cartesiano estava profundamente enganado em acreditar que a realidade poderia ser desvendada como uma estrutura lógica, através de princípios matemáticos. A observação científica poderia estabelecer relações, medidas e desvendar regularidades, mas não descobrir, em última instância, a razão e a finalidade da ocorrência dos fenômenos naturais. No limite, a verdade sobre as causas e finalidades dos fenômenos naturais só poderiam ser desveladas por Deus, quem os criou. Porém, os homens podem desvendar os fenômenos que ocorrem por sua ação e nos quais estão diretamente relacionados, os fenômenos históricos. Para ele, homens de diferentes culturas e épocas fazem questionamentos diferentes sobre o mundo e, portanto, produzem respostas diferentes e de formas diferentes. A diversidade de usos, costumes, valores e realizações artísticas 
compõem uma visão de mundo específica. Daí se origina a diversidade dos objetos de Vico, das epopéias antigas a textos sacros e históricos. "Sua importância para a história do lluminismo consiste em sua insistência na pluralidade de culturas e, por conseguinte, na caracterização falaciosa da ideia de que existe apenas uma estrutura da realidade que o filósofo iluminado pode ver e descrever logicamente (Idem, 2001:6). Vico se dedica, então, a estudar os símbolos produzidos pelos homens como respostas aos questionamentos diversos que culturas diversas produzem em momentos de seu desenvolvimento histórico. A sabedoria poética é entendida por Vico como a sabedoria vulgar dos povos gregos e, portanto, desvendar os signos presentes nas sagas de Homero, por exemplo, significa compreender a mais importante expressão cultural da civilização grega, seus valores e suas indagações sobre a estrutura da realidade. Poderíamos dizer então que a grande questão de Vico é a compreensão da estrutura mitológica das mais diversas culturas, sendo que o mito deve ser entendido não como uma representação falaciosa da realidade que é corrigida pela investigação racional, mas sim como uma representação da estrutura mesma da visão de mundo dos povos.

Berlin segue analisando a filosofia do alemão J. G. Hamann. Segundo Berlin, a filosofia de Hamann está baseada na ideia de que "a razão é impotente para demonstrar a existência de qualquer coisa e é um instrumento conveniente apenas para classificar e arranjar dados em padrões determinados; entender, para ele, é se comunicar, seja com o homem, seja com Deus" (Idem, 2001:7). A fé e os sentidos são os dois instrumentos básicos para que o homem entre em contato com a realidade, com o mundo que se compõe de símbolos que são indícios da ordem divina. Não existe um significado subjacente aos fenômenos que devem ser desvendados para que se conheça a verdadeira estrutura do real. O verdadeiro conhecimento é a percepção direta do objeto a se conhecer, e o conhecimento superior é a percepção direta de Deus, alcançada pela fé. A verdadeira operação da inteligência humana rumo ao conhecimento é a compreensão do individual, de suas características e diferenças com relação a outras entidades, e não a construção de generalizações que produzem conceitos para serem manipulados pela razão. Assim como em Vico, a realidade não se 
configura como uma estrutura escondida sob um conjunto de fenômenos aparentes, mas sim como um conjunto de símbolos a serem desvendados pelo espírito humano. "Deus fala conosco em palavras poéticas, endereçadas aos sentidos, não em abstrações que podemos aprender" (Hamann, apud Berlin, 2001:8). A história é o verdadeiro repositório da verdade, pois ela acumula a experiência de épocas, homens e culturas diferentes; o conhecimento humano armazenado na história vive através das imagens plásticas ou narrativas - criadas pelos homens para simbolizar o conhecimento sobre a realidade - ou Deus.

O terceiro grande pensador fundamental dessa tradição é outro alemão, o filósofo Johann Gotthfried von Herder que, segundo Berlin, procurará aplicar a filosofia de Hamann em uma tentativa de compreensão da história humana. Herder, assim como Vico e Hamann, entendia que, para compreendermos a ação humana, precisaríamos antes entender a estrutura de uma sociedade em termos de costumes, crenças e arte. A imersão profunda nas experiências de um povo é o método fundamental para a compreensão dos homens que compartilham de tais experiências. Substituir as tradições dos povos por ideias arbitrárias fruto da especulação racional é o grande risco da filosofia dos iluministas. Para Herder, o povo é o portador da alma de uma cultura; seus valores mais profundos sobrevivem através do povo. Tal filosofia pressupõe que toda cultura deva ser julgada por seus próprios princípios, seu significado não está dado por um elemento exterior, um sentido para além das circunstâncias nas quais ela floresce, se desenvolve e decai. O desenvolvimento do homem se dá, para Herder, na pluralidade da cultura à qual pertence. Porém, não se pode acreditar que a inteligência humana possa compreender toda a complexidade da história humana, de suas forças agentes, causas e consequências. Herder apresenta uma visão tipicamente cristã do debate de seu tempo sobre qual seria a força determinante para a formação da história: a guerra, a ação dos grandes homens ou um conjunto de pequenos acasos e ações individuais? Para Herder, no limite, a ação dos povos é conduzida por uma força que está além da completa compreensão humana: a ação da Providência. Os eventos terrestres têm um sentido último que só possui significado se reconhecermos a ação da providência na história, só possuem sentido "sub species aeternitatis".

O ponto fundamental da interpretação de Isaiah Berlin é que a crítica das luzes 
está fundada sobre um mesmo postulado em todos os autores por ele citados, qual seja, a incapacidade da razão humana de preencher de sentido a história e a sociedade humanas. Para ele, Burke também defende os preconceitos e percebe a história entendida não como filosofia do progresso, mas como acúmulo de experiências - a única fonte possível de legitimidade, a única forma de constituir uma ordem humana. A crítica burkeana a uma sociedade utilitária, vista apenas como um agregado de indivíduos unidos pelos laços advindos do contrato e obrigados apenas àquilo que nele está prescrito - o mundo de sofistas, economistas e calculadores - tem muitos pontos de contato com a concepção de Herder sobre os laços que mantém os homens unidos. Burke, como Herder, acredita que o verdadeiro elo entre os homens, o elo que permite a existência de uma sociedade, é formado por valores comuns, pelo compartilhamento de uma mesma tradição e pela consciência forte de um elo entre presente, passado e futuro.

\begin{abstract}
A sociedade é verdadeiramente um contrato. Contratos subordinados para objetos de interesse meramente ocasional podem ser dissolvidos com prazer; mas a sociedade não pode ser considerada como algo que não é melhor do que um acordo comercial de pimenta e café, cerâmica ou Tabaco, ou outro tipo de preocupação rasteira, para ser tomada como um interesse temporário e dissolvida pelo acordo das partes. Ela precisa ser olhada com outra reverência, pois não é um acordo submetido apenas a coisas concernentes à existência animal e grosseira, a coisas de uma natureza temporária e perecível. Ela é uma cooperação que reúne todo o conhecimento, toda a arte, toda virtude e toda perfeição. O fim dessa parceria não pode ser obtido no termino de uma geração, pois se ela se torna uma cooperação não apenas entre os vivos, mas entre aqueles que vivem, os que estão mortos e aqueles que ainda irão nascer. Cada contrato de cada estado particular não é senão a cláusula do grande contrato primevo da sociedade eterna, que liga as baixas e as altas naturezas, conecta o muito visível e o invisível, de acordo com um pacto fixo sancionado e inviolável que sustenta toda a natureza física e moral no seu devido lugar. (Burke, 1999, vol. 2:192-193).
\end{abstract}

A citação acima revela como há elementos na obra de Burke que permitem perceber afinidades com autores que apelam para elementos não-racionalistas, históricos e religiosos, ou seja, para fatores que reagem imediatamente às características fundamentais do pensamento iluminista. "A rejeição dos princípios centrais do iluminismo - universalidade, objetividade, racionalidade, capacidade de promover soluções permanentes para problemas da vida e do pensamento e (não 
menos importante) a acessibilidade ao método racional para qualquer um com os poderes adequados de observação e de pensamento lógico - ocorre em várias formas: conservadora ou liberal, reacionária ou revolucionária, dependendo do tipo de ordem sistemática que está sendo atacada" (Berlin, 2001:20). De fato, a filosofia de pensadores como Herder e Burke inspiraram diversos movimentos culturais e políticos, principalmente durante o século XIX. Basta citar, por exemplo, a incorporação de Herder por alguns autores no movimento do "Sturm und Dang" alemão e a influência de suas ideias no romantismo europeu de maneira geral. A busca por encontrar a verdadeira natureza humana no passado, na história, na cultura, e não na concepção abstrata de natureza humana e nos direitos naturais dos iluministas através de uma operação da razão marca uma distinção fundamental nos rumos da filosofia da história e da política nos séculos XIX e XX, e encontra no romantismo sua primeira expressão cultural de influência avassaladora.

\section{Burke e o lluminismo Inglês}

A leitura de Isaiah Berlin sobre a tradição contra-iluminista ganhou uma vasta repercussão nos estudos de história das ideias e tornou-se referência obrigatória para a compreensão do tema. Porém, no primeiro volume de sua obra Barbarism and Religion, de 1999, J. G. A. Pocock apresenta uma leitura diversa sobre a questão do iluminismo e de suas críticas. Seu estudo parte da vida e da obra de Edward Gibbon para uma compreensão mais ampla do contexto em que floresceram as ideias sobre a nova forma de interpretar e escrever a história na Europa do século XVIII. Para Pocock, desenvolveuse na Grã-Bretanha uma forma distinta de lluminismo, ao mesmo tempo influenciada e crítica do iluminismo de caráter francês, comumente tomado como o padrão para a definição do que é o lluminismo como fenômeno que ocorreu em toda a Europa. Autores como Gibbons e Burke seriam então representantes do lluminismo britânico, com suas características próprias, que Pocock procura traçar no primeiro volume de sua vasta obra sobre o historiador do declínio de Roma.

Na realidade, o conceito de lluminismo de Pocock é explicitamente formado em reação à caracterização geral do movimento feita por Franco Venturi. O historiador 
italiano nega que a Inglaterra tenha participado do movimento europeu do iluminismo. Para ele, até o final do século XVIII, com a publicação de obras de Jeremy Bentham, Richard Price (a quem Burke ataca no início das Reflections) e Thomas Paine, a Inglaterra não havia conhecido a formação de uma intelligentsia com propostas de guiar a sociedade. Pocock não nega a ideia central de Venturi de que na Inglaterra realmente não havia "philosophes" nos moldes franceses. O que ele questiona é a definição limitada do historiador italiano. Para Venturi, o iluminismo se configura como fruto de uma relação entre o poder e a filosofia, sobre a possibilidade do pensamento produzir mudança social e política. Contra tal concepção, Pocock defende sua própria definição, que procura antes caracterizar a relação do iluminismo com o movimento de mudança no âmbito social e político e com as mudanças na história do pensamento. Para ele, o iluminismo não é um fenômeno unificado, podendo ser distinguido através de uma "sociologia dos intelectuais", como faz Venturi; mas antes um vasto e diverso movimento da história das ideias, que deve ser caracterizado em suas diversas expressões e não unificado numa única definição. Pocock acredita que, de maneira geral, o lluminismo pode ser historicamente caracterizado de duas formas:

Em primeiro lugar, como a emergência de um sistema de estados, fundado em uma cultura e uma sociedade civil e comercial, que permitiu à Europa escapar das guerras de religião sem cair sob a hegemonia de uma única monarquia; em segundo lugar, como uma série de programas para reduzir o poder das igrejas e congregações e desafiar suas autoridades, produzindo transformações na sociedade civil (Pocock, 2003:7).

A definição de Pocock trabalha com duas distinções que se caracterizam por relacionar o movimento da história social e política com as possibilidades da história das ideias. A primeira característica ressalta as condições de transformação social das nações em Estados modernos e o processo de secularização que acompanha tais mudanças. Ou seja, o iluminismo se caracteriza como um pensamento que surge como possibilidade de pensar o mundo e o homem a partir das transformações ocorridas com o fim das guerras religiosas e a ascensão do Estado moderno. Já a segunda característica ressalta um questionamento que Pocock acredita ser fundamental para compreender o iluminismo para além da sua manifestação francesa, qual seja, a defesa de uma 
desconcentração do poder que leva em conta não apenas o lluminismo radical dos franceses como também a crítica política de Burke à concentração do poder monárquico, por exemplo. Pocock prefere a palavra no plural, "Enlightenments", do que o singular que limita o movimento numa só categoria geral e universal. A definição de Venturi também não se aplica com rigor à formação do iluminismo escocês. $O$ questionamento da ordem social e política vigente não faz parte das preocupações filosóficas imediatas de Hume, Smith ou Robertson. De fato, muitos dos filósofos escoceses do século XVIII estiveram em contato direto com os "philosophes" continentais e suas obras - para citar dois exemplos, vale lembrar as viagens de Hume pela França, seu contato com Rousseau e com as "societés" parisienses; além do debate de Adam Smith com as interpretações dos fisiocratas sobre economia política. Porém, não é possível afirmar, segundo Pocock, que os iluministas escoceses tenham formado uma intelligentsia com objetivos imediatos de transformação social. Mais uma vez a definição política de Venturi é colocada em questão através das análises contextuais de Pocock.

A relativa paz entre os Estados que a Europa da época das luzes vivia desde o tratado de Utrecht em 1713 era vista por muitos autores como fruto dos laços que o comércio criava entre as nações. A paz e o comércio estão indissociavelmente ligados no pensamento de alguns autores do século XVIII. O comércio era visto então como um escape para a violência que as paixões humanas poderiam gerar ${ }^{7}$. Unidas às trocas comerciais estão as trocas culturais e a divulgação de certos comportamentos e maneiras que irão caracterizar as sociedades do período. Burke, em seu ataque à Revolução Francesa, afirmará que os costumes são mais efetivos na manutenção dos laços sociais do que as leis criadas pelos "philosophes", e um dos grandes riscos da Revolução é justamente a destruição desses costumes.

A análise do pensamento de Burke, desde as Reflexões até as Cartas sobre a
Paz Regicida, pode ser indicada em um mesmo sentido. Ele estava defendendo
uma complexa ordem de governo - monárquica, clerical, aristocratica e
comercial - contra os desvios da mentalidade revolucionária, e o grupo social
ao qual ele mais temia não era nem a burguesia e nem o proletariado, mas
aquilo que a linguagem do século XIX chamaria posteriormente de

\footnotetext{
${ }^{7}$ Para mais sobre o tema, ver a obra fundamental de Hirschman, Albert (2002). As paixões e os Interesses. Argumentos a favor do capitalismo antes de seu triunfo. São Paulo: Record.
} 
intelligentsia. Ao comparar o antigo regime francês com o inglês, ele estava preocupado em mostrar que a riqueza da terra e a comercial eram mais harmoniosamente relacionadas na segunda, o que a tornava uma nação menos vulnerável à aliança dos especuladores intelectuais e financeiros que havia destruído a primeira (Pocock, 2005:39).

Pocock relata as circunstâncias históricas em que o lluminismo britânico surge e as suas relações e tensões com os movimentos protestantes e a igreja estabelecida. Para além dos detalhes históricos, o importante é retermos que, na concepção de Pocock, um dos elementos apontados como fundamentais para a caracterização do iluminismo francês, a reação anticlerical, não ocupou o mesmo espaço no debate britânico. Devido ao próprio histórico britânico de conflitos religiosos intestinos, à relativa liberdade de culto que se gozava na Inglaterra do século XVIII e ao fato de que os clérigos não compunham um estamento independente dentro da estrutura da administração dos assuntos públicos, a identificação entre ilustração e anticlericalismo não deu-se na Inglaterra como na França. "Não havia polarização entre clericais e anticlericais. Os últimos, evidentemente, abundavam e empregavam argumentos deístas e descrentes, mas, como Burke percebeu, eles não tinham razão para se organizar como 'uma faç̧ão dentro do Estado"” (Pocock, 2003:150). Ou, como afirma Himmelfarb, “(...) a variedade de seitas religiosas era, por si só, uma segurança de liberdade e, frequentemente, um instrumento de reforma social, além de salvação espiritual" (Himmelfarb, 2004:19) A preocupação de Burke com o surgimento de organizações como a "Sociedade dos Amigos da Revolução", à qual dirige as mais veementes reprovações, não denota apenas sua reação contra as ideias revolucionárias, mas antes um temor com relação ao fortalecimento na Inglaterra de "académies" ou "societés" nos moldes franceses, que promoviam antes a organização de ideias radicais. Pocock narra a passagem de Edward Gibbon pela França, o contato com os "philosophes" e os "salons" frequentados por eles. O radicalismo ateísta de alguns filósofos franceses como D'Holbach convertia-se também em radicalismo político, negando qualquer tipo de legitimidade à ordem política vigente. Em contraste, a moderação política dos filósofos como Hume, Burke e o próprio Gibbon levava a uma relação mais conservadora com a política. 


\begin{abstract}
Gibbon descobriu em 1763 o que mais tarde se acreditaria ser a grande virada na história do Iluminismo filosófico: no momento em que a Encyclopédie acreditou ter inaugurado o chamado "projeto iluminista", sustentado por alguns e incisivamente negado por outros, surge em conjunto a militância revolucionária explodindo na defesa de descristianização e da queda dos regimes. Burke está entre os originadores dessa percepção. Ele não desejava retornar ao passado medieval, mas via a modernidade enraizada na história cristã e medieval da Europa e incapaz de negar suas raízes sem autodestruir-se (Pocock, 2003:251).
\end{abstract}

Pocock ressalta que a convivência de Gibbon com a ilustração francesa levou-o a uma conclusão próxima daquilo que Burke expressaria anos mais tarde: a crença de que a ilustração representava uma campanha contra a religião cristã e a construção de uma civilização com base nos valores da razão: "O vasto empreendimento da Enciclopédia, conduzido por este tipo de cavaleiros (...) estes padres ateístas com uma intolerância especialmente sua, aprenderam a falar contra os monges com o mesmo espírito dos próprios monges" (Gibbon apud Pocock, 2003:250). Assim, vemos como Gibbon percebia no movimento das ideias aquilo que alguns anos depois Burke identificaria como realizado na Revolução Francesa. A identificação entre radicalismo político e ascensão dos "philosophes" ao centro do debate intelectual será um topos reiterado insistentemente durante a Revolução, não só por seus inimigos, mas por aqueles que acreditavam ter ela tomado um caminho perigoso de radicalização.

As raízes da relação entre a filosofia do iluminismo e a crença em uma transformação radical dos fundamentos da sociedade é muito bem descrita pelo filósofo e historiador alemão Reinhardt Koselleck. Em sua tese de doutorado, Crítica e Crise. Uma Contribuição à Patogênese do Mundo Burguês, Koselleck trata das raízes da crise política do século XVIII e do papel que a filosofia da História exerce na orientação desse fenômeno. Para ele, a ascensão do mundo burguês opera uma transformação fundamental na esfera do político: a separação entre a moral e o Estado - ou seja, entre a produção de objetivos individuais e a realização de uma determinada unidade entre sociedade e ordem política - supera a unidade soberana criada como saída para o problema da guerra civil. Dito de outro modo, o iluminismo produz uma unidade moral entre política e perspectiva de futuro, visando a superação do Estado absoluto através da potência da crítica, instrumento prescritivo da razão. Como dirá Koselleck, a filosofia da história expressa um juízo moral que, por sua vez, fornece a interpretação autêntica" 
da história (Koselleck., 1999:138): ela dirige a crise política ao fim pré-determinado pela decodificação do tempo perpetrada pela faculdade da crítica. Nas palavras de Koselleck, "no curso do desdobramento do cogito ergo sum cartesiano - a autogarantia dada ao homem que se desliga da religião -, a escatologia transforma-se em utopia. Planejar a história torna-se tão importante quanto dominar a natureza" (Idem, 1999:16). A crise política da modernidade aparece nos primeiros trabalhos do historiador alemão como resultado da secularização da escatologia em utopia e da filosofia da história como novo fundamento filosófico para a explicação e planejamento do futuro, mobilizada pelo iluminismo radical de "philosophes" como Rousseau e Lessing.

A reavaliação feita por Pocock do Essai sur l'étude de la littérature de Gibbon mostra como o iluminismo britânico partia de princípios que não resultavam num rompimento radical com os fundamentos da ordem política, como os do iluminismo francês. A acusação de Gibbon dirigida ao discurso preliminar da Encyclopédie escrito por D'Alembert, voltava-se ao fato de que o projeto promoveria a ascensão de uma única faculdade da inteligência humana contra todas as outras, e de que todo o conhecimento humano não baseado na razão dos "philosophes" estaria fatalmente legado à desaparição. Gibbon compreende o estudo da literatura como uma análise das letras européias que não visa à descoberta de regras gerais e leis causais, mas sim a formação de uma erudição humanista que permitiria ao estudioso construir relações entre os movimentos da história. O exercício historiográfico de Gibbon é muito mais um trabalho da imaginação do que propriamente uma especulação da razão. Burke, Hume, Gibbon, Robertson e outros pensadores do século XVIII dedicaram-se a escrever obras propriamente historiográficas ou de reflexão histórica, principalmente da GrãBretanha, para mostrar as raízes do governo e da sociedade inglesa de seu tempo. Nesse contexto, a história - e não o direito natural - é a ciência por excelência da compreensão política no iluminismo britânico em distinção à razão geométrica dos "philosophes" franceses. "Herder parte em busca do historicismo, Gibbon em busca da história; ele escreve história, não filosofia da história. Em um movimento que, de alguma forma, conduz a Burke, ele estabelece a imaginação de uma historiografia concebida em termos 
clássicos e neoclássicos" (Pocock, 2003:257-258).

A partir dos estudos de Pocock e de outros autores da academia de língua inglesa, a historiadora Gertrude Himmelfarb, em seu estudo The Roads to Modernity, parte também do principio de que não existe um "Projeto lluminista" único - assim como autores como Franco Venturi e Peter Gay pretenderam definir em suas obras - e dedica-se a estudar os iluminismos como projetos distintos de modernidade a partir das ideias e conceitos fundamentais que caracterizam-nos. Ela descreve três movimentos distintos: o britânico, o francês e o americano. Para Himmelfarb, o iluminismo britânico está calcado na busca pelas "virtudes sociais", para a descoberta dos fundamentos da sociabilidade natural dos homens; o francês está fundamentado na afirmação da razão como parâmetro único de julgamento do mundo; e, por fim, o americano, que se preocupa em fundar a ordem política a partir da garantia da idéia de liberdade.

Os filósofos morais britânicos eram tanto sociólogos quanto filósofos; preocupados com as bases de uma sociedade humana saudável. Os franceses tinham uma missão mais exaltada: fazer da razão um princípio de governo da sociedade e da mente, "racionalizar" o mundo. Já os americanos, mais modestamente, dedicaram-se a criar uma "nova ciência da política" que buscaria estabelecer uma nova república sobre os fundamentos da liberdade (Himmelfarb, 2004:19).

A ideia central que Himmelfarb acredita unir uma diversidade de autores britânicos é a crença comum em um "senso moral" incondicionalmente ligado à natureza humana. A filosofia do "moral sense" (ou "moral sentiment") nasceria com o Duque de Shaftesbury e ganharia forma na filosofia de autores como Hutcheson, Butler, Ferguson, Hume e Adam Smith. Locke, o mais importante filósofo moral inglês até o século XVIII, não atribuía aos homens nenhuma ideia inata, já que a mente humana era uma "tabula rasa" pronta a ser preenchida com sensações e experiências. O senso moral do homem seria desenvolvido tendo em vista a realização dos interesses e da felicidade comum, para evitar a dor e promover o prazer. Na filosofia moral de Locke encontra-se a raiz do empirismo e do utilitarismo. Porém, no início do século XVIII, o Duque de Shaftesbury escreveria uma obra considerada o início da filosofia dos sentimentos morais, justamente em oposição ao Essay on Human Understanding de Locke, escrito 10 anos antes. Shaftesbury afirma que a virtude é fruto de um "moral sense", um senso inato do certo e do errado, comum a todos os homens. Religião, interesse e mesmo 
razão são apenas elementos secundários, que suportam e justificam o sentimento natural da moral humana. O senso moral inato também produz "natural affection", ou seja, um sentimento natural de afeição a outros homens e ao convívio em sociedade. A afeição natural e não o interesse - seja o interesse utilitarista ou o interesse que subjaz aos diversos tipos de contratualismo - produzem o laço social e o "senso moral" inato que permite aos homens conviver em comunidade. A virtude não pode ser fruto de uma motivação fundamentalmente egoísta como o interesse; mesmo quando age errado, o homem não perde a distinção moral. Os vícios são fruto dos excessos das paixões humanas. A moral natural de Shaftesbury transforma-se numa ética social, na medida em que a virtude conduz ao bem comum. O contraste entre a filosofia moral de Shaftesbury e o jusnaturalismo de Hobbes e Locke é patente. A natureza não é um estágio distinto da vida em sociedade, nem a sociedade é fruto de um contrato que, antes de tudo, é um recurso para corrigir distúrbios surgidos no estado de natureza fruto dos vícios humanos. O vício e a virtude são dimensões de um mesmo estado humano, e são explicados a partir do reconhecimento do "moral sense" como elemento fundamental da vida em sociedade.

A mais importante obra sobre a natureza da moralidade desde Shaftesbury é o estudo de Adam Smith, The Theory of Moral Sentiments. É importante distinguir que Smith prefere o termo "sentiments" e não "sense", como usava Shaftesbury. Smith fala de sentimentos, pois, para ele, a moral é caracterizada por um conjunto de qualidades que os homens desejam e que conduzem à perfeição de sua natureza. Porém, não devemos entender a busca da perfeição da natureza humana como um sentimento egoísta, como amor-próprio. “A virtude agrada por si mesma. Já o vício certamente desagrada, não por conta de uma reflexão racional sobre ele, mas pelo que é despertado pelo 'senso e sentimento imediato'" (Himmelfarb, 2004:38). Os sentimentos morais, como a simpatia e a benevolência, nascem não da percepção do homem sobre seu próprio sofrimento, mas sim do ato de imaginar o sofrimento do outro. Os sentimentos morais em Smith são fruto de uma operação da imaginação, a faculdade humana por excelência do iluminismo britânico. Sentimentos como a simpatia e a benevolência 
conduzem o homem à virtude e, portanto, à melhor forma de produzir o bem comum.

Há ainda um outro elemento que subjaz à filosofia do iluminismo escocês e que nos ajuda a compreender boa parte do contexto no qual a crítica burkeana aos direitos naturais se informa. A crença essencial no aperfeiçoamento humano, no progresso moral associado ao progresso material da Europa do século XVIII, é encontrada especialmente no iluminismo escocês, no qual a ideia de uma "Europa do comércio e das luzes" é associada à expectativa de um "adestramento dos costumes", ou, em outras palavras, a uma expansão da civilização. A expressão mais célebre dessa interpretação encontra-se na obra de Adam Smith. Em sua obra An Inquirity in the Nature and Causes of the Wealth of Nations, Smith desenvolve um modelo de formas sociais possíveis, designando aquelas mais ou menos adequadas às transformações econômicas de seu tempo. Para Smith, uma sociedade pode existir em três estados: o progressivo, o estacionário e o decadente (advancing, stationary and declining state) (Smith, 1836:65). O estado progressivo representa o "curso natural das coisas" (natural course) nas nações civilizadas, nas quais o homem goza de "liberdade perfeita" (perfect liberty) para buscar aquilo que the parece vantajoso (Idem, 1836:101). O estado de declínio, por outro lado, existe em sociedades nos quais as condições sociais, econômicas e políticas - a superpopulação, a ausência de liberdade, a desordem civil causada por guerras internas ou externas - impedem que os homens dediquem-se à atividade econômica ativa: a transformação do tempo e do espaço em riqueza material (Idem, 1836:138). O que faz a superioridade objetiva do estado progressivo é o reconhecimento de que ele é o único dos três que permite a maximização de condições da felicidade humana, permitindo que a potência da ação humana se desenvolva em sua forma mais "otimizada". Taguieff chama a tenção para o fato de que os estados progressivo e decadente são acompanhados em diversos momentos por metáforas orgânicas: enquanto o primeiro é apresentado com o estado de "vigor e de saúde perfeitas", o segundo é apresentado como "o cansaço e a inércia" dos corpos doentes (Taguieff, 2004:181).

Smith apresenta a relação entre o progresso social e a existência de um "espírito comercial" responsável por domesticar os costumes, arrefecer a guerra e transformar as relações entre as nações. "O comércio e as manufaturas introduziram gradualmente a ordem e o bom governo, e com eles a liberdade e a segurança dos indivíduos, entre os 
habitantes do campo, que haviam antes vivido numa condição quase contínua de guerra com seus vizinhos e de dependência servil em relação a seus superiores" (Smith, 1836:84). O que resulta dessa união entre a ideia de progresso e o desenvolvimento do comércio e da indústria é o conceito de civilização tão caro ao iluminismo escocês: ele passa a descrever uma "condição moral" encontrada em determinados povos que atendem a determinados critérios ao mesmo tempo em que descreve o percurso desses povos no tempo histórico. "A 'sociedade civil' não tem o sentido que possui com Locke, onde se definia por oposição ao estado de natureza, nem o sentido que terá com Hegel, definindo-se por oposição ao Estado. O adjetivo 'civil' não é compreendido senão com referência ao processo de 'civilização'” (Taguieff, 2004:108).

O esforço de Himmelfarb é traçar uma continuidade que nasce com a crítica de Shaftesbury a Locke persiste através de vários autores até chegar a Burke. Para ela, assim como para Pocock, Burke é um autor característico do iluminismo britânico, e não um contra-iluminista, como Berlin e Sternhell afirmam. As primeiras obras de Burke, como Vindication on Natural Society e The Origin of Our Ideas of the Sublime and Beautiful, de caráter mais especulativo, expressam bem sua afinidade com a filosofia moral escocesa, especialmente com Adam Smith. A tese central do tratado estético de Burke procura afirmar que a diversidade de raciocínios e gostos humanos está assentada em sentimentos que são comuns a todas as criaturas humanas. Para Burke, os homens compartilham de "common feelings" ou "natural feelings", ou seja, de sentimentos que caracterizam os homens enquanto tal, que permitem identificar o pertencimento a uma mesma natureza. Burke afirma que "os sentimentos e a imaginação compreendem o espírito muito antes da razão ser capaz de se juntar ou se opor a eles" (Burke, 1999, vol.1:76). Assim como Smith, Burke acredita que a simpatia e a paixão são os sentimentos por excelência que nos movem em direção a outros homens, que produz o interesse por aquilo que "concerne aos outros". Burke afirma que a "virtude"(virtue) e a "sabedoria"(wisdom) devem ser os valores fundamentais para a condução dos assuntos públicos, e não a "razão" ou "direitos universais", como orienta a reflexão política do iluminismo francês. Para Himmelfarb, a ideia de virtude na obra de Burke relaciona-se 
diretamente com os sentimentos e opiniões sobre a moral herdados pelos costumes e preconceitos, ou seja, pela tradição. Nas Reflections, Burke fala de "presumptive wisdom", ou seja, uma sabedoria tida como tal pelos costumes, e não pela característica auto-evidente da razão.

O que nos importa reter aqui é que a interpretação de Himmelfarb nos mostra que a virtude, o sentimento por excelência que Shaftesbury relacionava com o "moral sense", aparece no pensamento de Burke como o fruto da sabedoria moral do homem acumulada desde tempos imemoriais. Os "moral feelings" de Burke estão muito mais próximos dos "moral sentiments" de Hume e Smith, pois não são inatos, mas antes pregados nos sentimentos humanos por meios dos preconceitos. A defesa da tradição, ou seja, dos costumes, sentimentos e preconceitos de um povo como cerne da condução da política seria então o elo, para Himmelfarb, entre a reflexão política de Burke e a teoria dos sentimentos morais.

\section{Conclusão}

Nossa intenção no presente trabalho foi compreender algumas das mais importantes contribuições no campo da história do pensamento político sobre o lugar que Burke exerce no panorama do pensamento ocidental. A partir de seus princípios mais fundamentais - o problema das massas como poder constituinte e o universalismo do direito de participação política - a Revolução Francesa coloca em questão todas as bases que fundamentavam as ordens políticas existentes até então. Ora, Burke percebe nesses princípios justamente o grande risco de abstração da política que, culminando com a Declaração Universal dos Direitos do Homem e do Cidadão, nega a validade de qualquer fundamento político que não tenha como origem o indivíduo dotado de direitos naturais. Poderíamos afirmar que os principais problemas concernentes à tradição da filosofia política moderna estão presentes de alguma forma na reflexão crítica de Burke. O filósofo Isaiah Berlin nos mostra como a reação ao racionalismo e ao iluminismo se dá justamente por tal filosofia alçar a razão como a única faculdade capaz de proferir julgamentos sobre o mundo e sobre os homens. 
Em contraposição a Berlin, as ideias de J. G. A. Pocock apresentam uma leitura sobre Burke não como um contra-iluminista, mas como mais um participante do movimento intelectual do iluminismo britânico. Pocock procurará caracterizar o iluminismo através de uma contextualização histórica, na qual as ideias comuns circulam em uma circunstância histórica específica. Para Pocock - e para Himmelfarb depois dele - o iluminismo britânico distingue-se justamente pelo compartilhamento de princípios teóricos específicos - o papel da história e da erudição na reflexão política e a teoria dos sentimentos naturais, por exemplo -, distintos dos princípios do iluminismo francês. 0 erro está em opor razão e irracionalismo, iluminismo e contra-iluminismo. A seu modo, o iluminismo britânico não é um contra-iluminismo, pois não é apenas a negação do iluminismo de corte francês, mas é uma outra forma de dar conta dos problemas postos pelo desenvolvimento do pensamento moderno a partir de outros princípios.

Nos parece que a distinção das leituras de Berlin e Pocock refletem justamente a diferença entre a matriz teórica da qual ambos provém. Berlin produz uma história das ideias através da livre associação do pensamento de diversos autores, traçando afinidades e contraposições sem considerar as circunstâncias nas quais o pensamento é produzido. Berlin dá continuidade à tradição da história das ideias de Arthur Lovejoy, onde os conceitos emergem do pensamento dos autores e são postos num contínuo diálogo, sem levar em conta a articulação entre pensamento e contexto ${ }^{8}$. Por outro lado, Pocock busca reconhecer as relações históricas de circulação e recepção de ideias. Sua imagem do iluminismo britânico traça não só a afinidade, mas antes a relação factual entre o diálogo e a influência de determinados autores sobre outros, como no caso da relação entre as ideias de Gibbon e Burke, e por extensão de ambos com a filosofia escocesa, no primeiro volume de Barbarism and Religion. É fundamental retomarmos Pocock, quando afirma que,

Para dizer que as Reflexões são um "clássico" do conservadorismo inglês - a despeito do fato de Burke não ser inglês - precisamos nos lembrar que a obra tomou forma em um determinado contexto e continuou a tomar formas diferentes em contextos diferentes. Isso pode significar, dentre outras coisas,

\footnotetext{
${ }^{8}$ Para mais, ver: Lovejoy, Arthur. 2006. A Grande Cadeia do Ser. São Paulo: Palíndromo.
} 
que o seu conservadorismo é de um tipo particularmente inglês. A obra foi escrita para defender o sistema político inglês - o governo da Grã-Bretanha e da Irlânda pela monarquia e pela aristocracia segundo a concepção dos whigs do século XVIII - e os seus argumentos "conservadores" são baseados naqueles que o sistema já estava acostumado a usar para sua defesa (Pocock, 2005:7-8).

Assim, do ponto de vista metodológico, é importante ressaltar que trabalhar com a história das ideias políticas é, ao mesmo tempo, "retrabalhar constantemente as antinomias constitutivas da experiência moderna" (Rosanvallon, 2010:52), ou seja, compreender as formulações teóricas e institucionais à luz da história do desenvolvimento político das formaspolíticas modernas. Com isso não pretendemos conferir um caráter teleológico ao trabalho da história das ideias, no sentido de que as ideias convergiriam todas para a culminação da experiência liberal-democrática no ocidente. Ao contrário, o que buscamos é entender o pensamento político como espaço privilegiado - ao lado de outros, como a literatura, por exemplo - no qual se expõem as "questões, as perplexidades e as inovações" (Idem, 2010:52) das transformações históricas dos últimos três séculos, ao mesmo tempo em que nele encontramos a linguagem através do qual os atores políticos buscaram dar inteligibilidade à imaginação institucional e à ação política concreta. Essa ressalva metodológica pode ser compreendida como o principal instrumento para manter o trabalho da história das ideias a salvo do uso ideológico do "presentismo": localizar os discursos políticos em seu campo de conflito contextual pode nos ajudar a evitar que seja atribuído a eles uma "cegueira histórica" ao serem confrontados com etapas muito posteriores do desenvolvimento político da democracia.

Assim, no momento em que o conservadorismo transforma-se de "contrautopia", nas palavras de Mannheim, em uma formulação de um conjunto de instrumentos teóricos que se propõe a dar conta positivamente dos problemas da política, a obra de Burke torna-se uma referência fundamental. Ela pode descolar-se do contexto específico no qual é formulada e servir como instrumental teórico para a crítica cultural e para a formulação de ideologias políticas. Nesse sentido, o conservadorismo, entendido em seu contexto histórico especificamente inglês, pode ser transformado em um argumento político para disputa política no "espaço público". Porém, se a relação está clara do ponto de vista da história das ideias, a bibliografia burkeana ainda carece 
de um grande estudo histórico que contextualize a recepção de Burke na bibliografia das ideias políticas no século XIX e XX. Independente da caracterização de Burke como um contra-iluminista (Berlin) ou como um iluminista britânico (Pocock), nos parece claro que a obra de Burke emerge da crítica a uma certa vertente hegemônica da filosofia política moderna, no que tange às suas concepções sobre a história, a ordem política e a vida do homem em sociedade. Assim, não é de se espantar que, a despeito das ressalvas que se podem fazer ao localizar sua obra e sua atuação política no contexto do liberalismo britânico, seu trabalho tenha sido insistentemente reafirmado por diversas tendências da crítica à modernidade. O pensamento de Burke é a filosofia da crise, pois é formulado acima de tudo como reação, como despertar para a necessidade de defender princípios ameaçados pela filosofia de seu tempo. Não é absurdo o julgamento de alguns intérpretes ingleses ao afirmar que, se não fosse o advento da Revolução Francesa, Burke passaria a história como apenas mais um típico político whig, engajado nas causas dos liberais de seu tempo.

\section{Referências Bibliográficas}

Ayling, Stanley. 1990. Edmund Burke: His live and opinions. London: Cassell Publishers.

Berlin, Isaiah. 2001. Against the Current. Essays in the History of Ideas. Edited by Henry Hardy. Princeton: Princeton University Press.

Berlin, Isaiah. 2009. Idéias Políticas na Era Romântica. Ascensão e influência no pensamento moderno. Organização de Henry Hardy. São Paulo: Cia. das Letras.

Berlin, Isaiah. 1999. The Roots of Romanticism. Edited by Henry Hardy. Princeton: Princeton University Press.

Broadie, Alexander(ed.). 2003. Cambridge Companion to the Scottish Englihtenment. New York: Camberidge University Press.

Burke, Edmund. 1992. Further Reflections on the Revolution in France. Edited by Daniel E. Ritchie. Indianapolis: Liberty Found.

Burke, Edmund. 2000. On Empire, Liberty and Reform. Speeches and Letters. Edited by David Bromwich. Pennsylvania: Yale University Press.

Burke, Edmund. 2009. Selected Writings and Speeches of Edmund Burke. Edited by Peter J. Stanlis. Washington: Regenery Publishing. 
Burke, Edmund. 1999. Select Works of Edmund Burke. 4 vols. Foreword and Biographical note by Francis Canavan. Indianapolis: Liberty Found.

Burke, Edmund. 2001. Reflections on the Revolution in France. A Critical Edition. Edited by J. C. D. Clark. Stanford: Stanford University Press.

Burke, Edmund. 1997. Reflexões sobre a Revolução em França. Trad. de Renato de Assumpção Faria, Denis Fontes de Souza Pinto e Carmen Lídia Richter Ribeiro Moura. Brasília: Editora Universidade de Brasília.

Cobban, Alfred. 1929. Edmund Burke and the Revolt Against the Eighteenth Century: A Study of the Political and Social Thinking of Burke, Wordsworth, Coleridge, and Southey. London: Allen \& Unwin.

Conniff, James. 1994. The Useful Cobbler. Edmund Burke and the Politics of Progress. New York: State University of New York Press.

Crowe, lan (ed.). 1997. The Enduring Edmund Burke. Bicentennial Essays. Wilmington: Intercollegiate Studies Institute.

Florenzano, Modesto.1994. As Reflexões sobre a Revolução em França de Edmund Burke: Uma Revisão Historiográfica. Tese (Doutorado em História Social) Universidade de São Paulo.

Koselleck, Reinhardt. 1999. Crítica e Crise. Contribuição à Patogênese do Mundo Burguês. Rio de Janeiro: EdUerj: Contraponto.

Hazard, Paul. 2009. La crise de la Conscience Européenne. 1680-1715. Paris: Fayard.

Himmelfarb, Gertrud. 2006. The Moral Imagination. Chicago: Ivan R. Dee Publisher.

Himmelfarb, Gertrud. 2004. The Roads to Modernity. The British, French, and American Enlightenments. New York: Vintage Books.

Hirschman, Albert. 2002. As paixões e os Interesses. Argumentos a favor do capitalismo antes de seu triunfo. São Paulo: Record.

Kirk, Russell. 1967. Emund Burke. A Genius Reconsidered. New York, Arlington House.

Kirk, Russell. 1978. The Conservative Mind. From Burke to Eliot. Indiana: Gateway Edition.

Kirk, Russell. 1993. The Politics of Prudence. Delaware: ISI Books, 1993.

Kramnick, Isaac. 1977. The Rage of Edmund Burke: Portrait of an Ambivalent Conservative. New York: Basic Books.

Löwy, Michel; Sayre, Robert. 1993. Romantismo e Política. Rio de Janeiro, Paz e Terra.

Mannheim, Karl. 1968. Ideologia e Utopia. Rio de Janeiro: Zahar Editores.

Mannheim, Karl. 1986. O pensamento conservador. In: MARTINS, J. S. (1986). Introdução crítica à sociologia rural. 2a ed. São Paulo: HUCITEC.

Nisbet, Robert. 1987. O Conservadorismo. Tradução M. F. Gonçalves de Azevedo. Lisboa: Editorial Estampa. (Ciências Sociais Temas, no1) 
Nisbet, Robert. 1992. Os Filósofos Sociais. Tradução de Yvette Vieira Pinto de Almeida. Brasília, Editora Universidade de Brasília.

Parkin, Charles. 2001. The moral Basis of Burke's Political Thought. An Essay. New York: Cambridge University Press.

Pocock, John Grenville Agard. 1987. Ancient Constitution and Feudal Law. New York: Cambridge University Press.

Pocock, John Grenville Agard. 2003. Barbarism and Religion. Vol.1. New York: Cambridge University Press.

Pocock, John Grenville Agard. 2005. Introduction "Reflections on the Revolution in France". Indianapolis: Hackett.

Pocock, John Grenville Agard. 2003. Linguagens do Ideário Político. São Paulo: EDUSP.

Pocock, John Grenville Agard. 1985. Virtue, Commerce and History. New York: Cambridge University Press.

Rosanvallon, Pierre. 2010. Por uma História do Político. São Paulo: Alameda.

Smith, Adam. 1836. An Inquirity on the Nature and Causes of the Wealth of Nations. Londres: William Clowes and Sons.

Stanlis, Peter J. 1986. Edmund Burke and the Natural Law. Louisiana, Huntington House.

Sternhell, Zeev. 2006. Les Anti-Lumières. Du XVIII siècle à la guerre froide. Paris: Fayard.

Strauss, Leo. 1971. Natural Right and History. Chicago: University of Chicago Press.

Taguieff, Pierre-André. 2004. Le sens du progrès. Une approche historique et philosophique. Paris: Éditions Flammarion.

Venturi, Franco. 2003. Utopia e Reforma no lluminismo. Florianópolis: Edusc. 